\title{
QT interval in healthy dogs: which method of correcting the QT interval in dogs is appropriate for use in small animal clinics? ${ }^{1}$
}

\author{
Maira S. Oliveira² ${ }^{2}$ Ruthnéa A.L. Muzzi ${ }^{3 *}$, Leonardo A.L. Muzzi ${ }^{3}$, Marcos Cherem \\ and Matheus M. Mantovani ${ }^{3}$
}

\begin{abstract}
Oliveira M.S., Muzzi R.A.L., Muzzi L.A.L., Cherem M. \& Mantovani M.M. 2014. QT interval in healthy dogs: which method of correcting the QT interval in dogs is most appropriate for use in small animal clinics? Pesquisa Veterinária Brasileira 34(5):469472. Departamento de Medicina Veterinária, Universidade Federal de Lavras, Cx. Postal 3037, Lavras, MG 37200-000, Brazil. E-mail: ralmuzzi@dmv.ufla.br

The electrocardiography (ECG) QT interval is influenced by fluctuations in heart rate (HR) what may lead to misinterpretation of its length. Considering that alterations in QT interval length reflect abnormalities of the ventricular repolarisation which predispose to occurrence of arrhythmias, this variable must be properly evaluated. The aim of this work is to determine which method of correcting the QT interval is the most appropriate for dogs regarding different ranges of normal HR (different breeds). Healthy adult dogs ( $\mathrm{n}=130$; German Shepherd, Boxer, Pit Bull Terrier, and Poodle) were submitted to ECG examination and QT intervals were determined in triplicates from the bipolar limb II lead and corrected for the effects of HR through the application of three published formulae involving quadratic, cubic or linear regression. The mean corrected QT values (QTc) obtained using the diverse formulae were significantly different $(\rho<0.05)$, while those derived according to the equation $\mathrm{QTcV}=\mathrm{QT}+0.087(1-\mathrm{RR})$ were the most consistent (linear regression). QTcV values were strongly correlated $(\mathrm{r}=0.83)$ with the QT interval and showed a coefficient of variation of $8.37 \%$ and a $95 \%$ confidence interval of $0.22-0.23$ s. Owing to its simplicity and reliability, the QTcV was considered the most appropriate to be used for the correction of QT interval in dogs.
\end{abstract}

INDEX TERMS: Electrocardiogram, heart rate, dog, QTc.

\begin{abstract}
RESUMO.- [Intervalo QT em cães hígidos: qual método de correção para o intervalo QT é mais apropriado na clínica de pequenos animais?] 0 intervalo QT do eletrocardiograma (ECG) é influenciado por variações da frequência cardíaca (FC), o que pode levar a erros na interpretação de sua duração. Considerando que as alterações na
\end{abstract}

\footnotetext{
${ }^{1}$ Received on September 24, 2013.

Accepted for publication on March 25, 2014.

${ }^{2}$ Departamento de Clínica e Cirurgia Veterinária, Escola de Veterinária, Universidade Federal de Minas Gerais (UFMG), Av. Pres. Antônio Carlos 6627, Cx. Postal 567, Belo Horizonte, MG 30123-970, Brazil. E-mail: maira_oliveira@yahoo.com

${ }^{3}$ Departamento de Medicina Veterinária, Universidade Federal de Lavras, Cx. Postal 3037, Lavras, MG 37200-000, Brazil. E-mails: ralmuzzi@ dmv.ufla.br, lalmuzzi@dmv.ufla.br, matheus2mvet@gmail.com; *Corresponding author: ralmuzzi@dmv.ufla.br

${ }^{4}$ ECOMED Medicina Diagnóstica, Hospital Vaz Monteiro, Rua Costa Pereira 125 , Lavras, MG 37200-000. E-mail: marcoscherem@hotmail.com
}

duração do intervalo QT refletem anormalidades da repolarização ventricular, as quais predispõem a ocorrência de arritmias, esta variável deve ser devidamente avaliada. 0 objetivo deste trabalho foi determinar qual método de correção do intervalo QT é mais adequado para os cães, considerando-se diferentes intervalos de FC normais. Cães adultos saudáveis, de diferentes raças $(\mathrm{n}=130$; Pastor Alemão, Boxer, Pit Bull Terrier e Poodle) foram submetidos ao exame eletrocardiográfico, no qual se determinaram os intervalos QT a partir da derivação bipolar II e foram corrigidos os efeitos da FC por meio da aplicação de três fórmulas, envolvendo regressão quadrática, cúbica ou linear. Os valores do QT corrigido (QTc) obtidos utilizando as diversas fórmulas foram significativamente diferentes $(\rho<0,05)$, sendo os derivados da equação QTcV = QT + 0,087 (1- RR), os mais consistentes (regressão linear). Valores de QTcV apresentaram correlação significativa e de alta magnitude $(\mathrm{r}=0,83)$ com o intervalo QT, baixo coeficiente de variação $(8,37 \%)$ e 
intervalo de confiança de $95 \%$ de $0,22-0,23$ s. Devido à confiabilidade dos dados, o QTcV foi considerado o mais apropriado para ser utilizado para a correção do intervalo QT em cães, além de ser um método de fácil execução.

TERMOS DE INDEXAÇÃO: Eletrocardiograma, frequência cardíaca, cão, QTc.

\section{INTRODUCTION}

The QT interval, measured in the electrocardiogram (ECG), comprises the length from the onset of the QRS complex to the end of the $\mathrm{T}$ wave in the cardiac cycle, and represents ventricular depolarisation and repolarisation (Tilley 1992). The QT interval exhibits an inverse relationship to the heart rate (HR) and its measurement should be corrected in order to improve its diagnostic utility (Harada et al. 2010). Precise estimation of the QT interval duration is clinically relevant because abnormal values may indicate the occurrence of cardiac alterations. The development of cardiac diseases concurs with alterations in autonomic control of the heart (Vanderlei et al. 2009, Harada et al. 2010) which are reflected on ECG parameters that are HR dependent, as the QT interval.

Increases in HR, commonly detected in dogs with degenerative mitral valve disease or cardiomyopathy, with accompanying decreases in QT duration could be masking an inherent increase in QT interval (Dennis et al. 2002, Rasmussen et al. 2011). For human patients it is demonstrated that long QT interval suggests hypertension, HIV co-infection, hepatitis $\mathrm{C}$ or a propensity to torsade de pointes, a life threatening polymorphic ventricular tachycardia (Kay et al. 1983, Al-Khatib et al. 2003, Nordin et al. 2006, Peng et al. 2006, Topilski et al. 2007), whereas short QT interval indicates genetic abnormalities or digitalis intoxication (Gaita et al. 2003, Garberoglio et al. 2007).

The formula that adequately corrects QT interval for increases in HR was therefore required. Formulae for calculating corrected QT interval (QTc) have been available since 1920 (Bazett 1920, Fridericia 1920) and various alternative methods have been studied, mainly in toxicology researches (Spier et al. 2001, Davey 2002, Tattersall et al. 2006, Ollerstam et al. 2007). In medicine, the Bazett correction is worldwide employed due to its simplicity and reliable data. In veterinary medicine, however, such correction is not the most suitable due to the higher normal $\mathrm{HR}$ values for dogs, compared to men (Spier et al. 2001, Davey 2002). Despite the importance of the QTc in cardiology, it has been lead to a second field in veterinary medicine and there is no consensus regarding the adoption of a simple and reliable correction formula for dogs.

A number of correction formulae are currently used, most of which were derived for analyzing human data, some for analyzing anaesthetized animals or animal models for toxicology assessments. Little information, however, is available on how to correct the QT interval for clinical practice, considering different HR ranges (due to different breeds) in conscious healthy dogs. The aim of the present study was to determine the suitable QT interval correction method obtained from healthy dogs, considering different breeds for the assessment of different HR ranges. In order to achieve this goal it was performed the formulae proposed by Bazett 1920, Fridericia 1920, and Van de Water et al. 1989.

\section{MATERIALS AND METHODS}

Experimental procedures were done in accordance with the Committee of Ethics in Animal Research of the Institution, taking into consideration the rules of COBEA (Colégio Brasileiro de Experimentação Animal) under protocol number 029/10.

The sample studied was comprised by 130 adult dogs, 1 to 4 years old, clinically healthy (physical examination) with no abnormalities in echocardiography examination. In order to include small, medium and large dogs, different breeds were considered as follows: German shepherd $(\mathrm{n}=60 ; 30$ males and 30 females; mean weight of $30.2 \pm 3.98 \mathrm{~kg})$, Boxer $(\mathrm{n}=36,16$ males and $20 \mathrm{fe}-$ males; mean weight of $20.5 \pm 2.37 \mathrm{~kg}$ ), Pit Bull Terrier ( $\mathrm{n}=12,8$ males and 4 females; mean weight of $24.9 \pm 1.51 \mathrm{~kg}$ ), and Poodle $(\mathrm{n}=22,11$ males and 11 females; mean weight of $6.2 \pm 1.3 \mathrm{~kg}$ ).

The ECG was done as usual (Tilley 1992) and standard bipolar limb leads (I-III) and augmented unipolar leads (aVR, aVL and $\mathrm{aVF}$ ) were recorded at a speed of $50 \mathrm{~mm} / \mathrm{s}$ and a sensitivity of $1 \mathrm{~cm}=1 \mathrm{mV}$. All tracings considered in this work were normal and the waves and intervals were easily identified. Harte rate and QT interval values were obtained in triplicates from the bipolar II traces, and all analysis were done by the same researcher. For calculation of the heart rate it was considered the duration of RR interval. QTc values were obtained from the following equations: $\mathrm{QTcB}=\mathrm{QT}^{*}(\mathrm{RR})^{1 / 2}$ (Bazett 1920); $\mathrm{QTcF}=\mathrm{QT}^{*}(\mathrm{RR})^{1 / 3}$ (Fridericia 1920) and QTcV = QT + 0.087(1- RR) (Van de Water et al. 1989).

The QTcB, QTcF, and QTcV parameters were obtained as triplicates and the mean values were studied by descriptive analysis and analysis of variance (ANOVA) followed by Tukey post-test $(\rho<0.05)$. Additionaly it was determined the Pearson's correlation coefficient between QT and QTcB, QTcF, QTcV values. The statistical analyses were performed using SISVAR software (Ferreira 2000).

\section{RESULTS}

Mean HR, QT interval and QTc values are shown in Table 1. The minimum and maximum values of QTcB, QTcF and QTcV were $0.17 / 0.39 s, 0.15 / 0.32$ s and $0.16 / 0.28$ s respectively, while the coefficients of variation of these parameters were, respectively, $11.89 \%, 10.38 \%$ and $8.37 \%$.

There was a negative correlation between the HR and the QT interval $(r=-0.69 ; \mathrm{p}<0.05)$. Poodle dogs, which had the highest mean HR value, showed the smallest mean QT value, whereas German Shepherds, with the smallest mean HR value, had the highest mean QT value. A moderate positive correlation was observed between QT interval and weight $(\mathrm{r}=0.374 ; \mathrm{p}<0.05)$. A high correlation $(\mathrm{r}=0.830$; $\mathrm{p}<0.05$ ) was detected between QT and QTcV, whereas the correlation between QT and QTcF $(r=0.68 ; \mathrm{p}<0.05)$ and between QT and QTcB $(r=0.32 ; \mathrm{p}<0.05)$ showed moderate or weak magnitude, respectively. The $95 \%$ confidence interval analisys for the QTcV values was from 0.22 to $0.23 \mathrm{~s}$.

\section{DISCUSSION}

This study demonstrated that the heart rate and body weight influence the QT interval. There was a negative correlation between HR and QT interval similar as demonstrated by Spence et al. 1998. Such finding highlights the importan- 
Table 1. Corrected QT (QTc) values (mean \pm standard deviation) obtained from 130 adult healthy dogs using three different correction methods

\begin{tabular}{lccccc}
\hline \multicolumn{1}{c}{ Canine breed } & $\begin{array}{c}\text { Heart rate } \\
(\mathrm{bpm})\end{array}$ & $\begin{array}{c}\text { QT interval } \\
(\mathrm{s})\end{array}$ & $\begin{array}{c}\text { QTcB } \\
(\mathrm{s})\end{array}$ & $\begin{array}{c}\text { QTcF } \\
(\mathrm{s})\end{array}$ & $\begin{array}{c}\text { QTcV } \\
(\mathrm{s})\end{array}$ \\
\hline German Shepherd $(\mathrm{n}=60)$ & $102.28 \pm 25.51$ & $0.20 \pm 0.02$ & $0.26 \pm 0.02^{\mathrm{a}}$ & $0.24 \pm 0.02^{\mathrm{b}}$ & $0.23 \pm 0.01^{\mathrm{c}}$ \\
Boxer $(\mathrm{n}=36)$ & $150.89 \pm 27.15$ & $0.18 \pm 0.02$ & $0.29 \pm 0.03^{\mathrm{a}}$ & $0.25 \pm 0.03^{\mathrm{b}}$ & $0.23 \pm 0.02^{\mathrm{c}}$ \\
Poodle (n = 22) & $152.73 \pm 32.39$ & $0.16 \pm 0.03$ & $0.26 \pm 0.04^{\mathrm{a}}$ & $0.22 \pm 0.03^{\mathrm{b}}$ & $0.21 \pm 0.02^{\mathrm{c}}$ \\
Pit Bull Terrier (n =12) & $133.75 \pm 26.89$ & $0.18 \pm 0.02$ & $0.27 \pm 0.02^{\mathrm{a}}$ & $0.23 \pm 0.01^{\mathrm{b}}$ & $0.23 \pm 0.01^{\mathrm{c}}$ \\
Total (n = 130) & $127.00 \pm 35.93$ & $0.19 \pm 0.03$ & $0.27 \pm 0.03^{\mathrm{a}}$ & $0.24 \pm 0.02^{\mathrm{b}}$ & $0.23 \pm 0.02^{\mathrm{c}}$ \\
\hline QTcB = QT interval corrected as Bazett (1920), QTcF = QT interval corrected as Fridericia \\
(1920), and QTcV = QT interval corrected according to Van de Water et al. (1989). Diffe- \\
rent letters indicate statistical differences (ANOVA - Tukey $\rho<0.05)$.
\end{tabular}

ce of correctly evaluate QT interval, by using a correction formula, as variations in HR may mask abnormalities in QT interval which may be diagnosed.

As heart diseases are one of the most frequent problems face by veterinarians, animals must be evaluated as more complete as possible. The development of heart disease and heart failure leads to variations in the autonomic control of the heart, primarily enhancing the HR (Little et al. 2005). Considering high HR, QTcB showed great variability from the original QT interval, suggesting that Bazett formula should not be employed, corroborating previous researches (Spence et al. 1998, Batey \& Doe 2002, King et al. 2006). For men, whose normal mean HR is around $60 \mathrm{bpm}$, the Bazett's correction is properly used, different from dogs whose normal HR range is higher. Taken together the large dispersion of the QTcB values and the poor correlation between then and the QT interval, indicate that Bazett's correction is not suitable for dogs.

On the other hand, the correct QT intervals (QTcF values) obtained by application of the formula proposed by Fridericia (1920) showed less variability than the QTcB values. Although QTcF may be somewhat more appropriate for dogs, as previously suggested (Davis \& Middleton 1999, Spier et al. 2001), the parameter showed a moderate correlation with QT interval, indicating that the use of Fridericia's formula should not be recommended for dogs.

Bazett's and Fridericia's formulae fail to describe the QT to RR functional relationship in the dog (Agudelo et al. 2011). The procedures for calculating QTcB and QTcF were originally formulated on the basis of human physiology and employ, respectively, quadratic and cubic corrections of HR. However, the HR of dogs is much higher than that found in humans and, hence, the correct QT values provided by such equations diverge greatly from the original QT intervals . In contrast, the simple linear equation proposed by Van de Water et al. (1989) yielded more consistent results for high HR. Thus, QTcV had the lowest coefficient of variation and the less variability, compared with the others. Moreover, the correlation between QTcV and QT was much stronger than those between QTcB or QTcF values and QT. It is suggested, therefore, that QTcV is the most appropriate way to correct QT interval in the clinical assessment of dogs, since it does not overcorrect the QT interval for high HR.

Another advantage of the QTcV formula is its simplicity in comparison with other proposals involving logarithmic (Matsunaga et al. 1997), covariance (Spence et al. 1998), exponential (Raunig et al. 2001), or linear (Davey 2002, King et al. 2006, Ollerstam et al. 2007, Sivarajah et al. 2010) analysis. These alternative methods are extremely valuable in toxicological studies since they are very reliable and yield QTc values that are not significantly influenced by HR. However, application of the formulae and interpretation of the results produced by these procedures is complex, and this will limit their use. In small clinical practice it is common the use of ECG equipments which provide no QTc or just the QTcB (not suitable for application in dogs), thereafter the veterinarian has to calculate the QTc handmade, following a suitable correction formula. In such situation a reliable and simple method is the most desired.

Data still need to be collected to cover a wide range of HR and weight body. This is clearly time consuming and is not feasible in clinics routines but it is necessary to establish normal reference values for different breeds (small, medium, large). However, our results are consistent with previous studies evaluating the appropriateness of correction formula in canine QTc data.

\section{CONCLUSION}

Results from the present study indicate that the method proposed by Van de Water et al. (1989) for correcting QT intervals is the most appropriate for application to dogs in small clinical practice because of its simplicity and reliability. The routine application of such approach would certainly assist the correct evaluation of the QT interval in order to precisely infer about abnormalities of the ventricular repolarization which predispose to occurrence of arrhythmias that must be diagnosis as early as better.

Acknowledgements.- To Fundação de Amparo à Pesquisa do Estado de Minas Gerais (Fapemig) and Conselho Nacional de Desenvolvimento Científico e Tecnológico (CNPq) for financial support.

\section{REFERENCES}

Agudelo C.F., Scheer P. \& Tomenendalova J. 2011. How to approach the QT interval in dogs - state of the heart: a review. Vet. Med. 56:14-21.

Al-Khatib S.M., Lapointe N.M.A., Kramer J.M. \& Califf R.M. 2003. What clinicians should know about theQT interval. J. Am. Med. Assoc. 16:21202127.

Batey A.J. \& Doe C.P.A. 2002. A method for QT correction based on beat-tobeat analysis of the QT/RR interval relationship in conscious telemetred beagle dogs. J. Pharmacol. Toxicol. Methods 48:11-19.

Bazett H.C. 1920. An analysis of the time-relations of electrocardiograms. Heart 7:353-367. 
Davey P. 2002. How to correct the QT interval for the effects of the heart rate in clinical studies. J. Pharmacol. Toxicol. Methods 48:3-9.

Davis A.S. \& Middleton B.J. 1999. Relationship between QT interval and heart rate in elderly park beagles. Vet. Rec. 145:248-250.

Dennis S.G., Summerfield N.J. \& Boswood A. 2002. Investigation of QT-interval dispersion in the electrocardiogram of 81 dogs. Vet. Rec. 151:7782.

Ferreira D.F. 2000. Análises estatísticas por meio Sisvar para Windows versão 4.0. 45a Reunião Anual da Sociedade Internacional de Biometria, São Carlos, SP, p.255-258.

Fridericia L.S. 1920. Die Systolendauer im Elektrokardiogramm bei normalen Menschen und bei Herzranken. Acta Med. Scand. 53:469-486.

Gaita F., Giustetto C., Bianchi F., Wolpert C., Schimpf R., Riccardi R., Grossi S., Richiardi E. \& Borggrefe M. 2003. Short QT syndrome: a familial cause of sudden death. Circulation 108:965-970.

Garberoglio L., Giustetto C., Wolpert C. \& Gaita F. 2007. Is acquired short QT due to digitalis intoxication responsible for malignant ventriculary arrhythmias? J. Electrocardiography 40:43-46.

Harada T., Fumiko I., Hamada M., Horie N., Nitta Y., Nitta K., Katsuoka H. \& Nakamura S. 2010. Circadian rhythm of heart-rate variability and autonomic cardiovascular regulation in Parkinson's disease. Auton. Neurosci. 158:133-140.

Kay G.N., Plumb V.J., Arciniegas J.G., Henthorn R.W. \& Waldo A.L. 1983. Torsade de pointes: the long-short initiating sequence and other clinical features: observation in 32 patients. J. Am. Coll. Cardiol. 2:806-817.

King A., Bailie M. \& Olivier N.B. 2006. Magnitude of error introduced by application of heart rate correction formulas to the canine QT interval. Ann. Noninvasive Electrocardiol. 11:289-298.

Little C.J.L., Reid S.W.J., Julu P.O.O. \& Hansen S. 2005. Non-invasive realtime measurements of cardiac vagal tone in dogs with cardiac disease. Vet. Rec. 156:101-105.

Matsunaga T., Mitsui T., Harada T., Inokuma M., Murano H. \& Shibutani Y. 1997. QT corrected for heart rate and relation between QT and RR intervals in beagle dogs. J. Pharmacol. Toxicol. Methods 38:201-209.

Nordin C., Kohli A., Beca S., Zaharia V., Grant T., Leider J. \& Marantz P. 2006. Importance of hepatitis $\mathrm{C}$ coinfection in the development of QT prolongation in HIV-infected patients. J. Electrocardiol. 39:199-205.

Ollerstam A., Visser S.A.G., Duker D., Forsberg T., Persson A.H., Lars B., Nilsson L.B., Björkman J.A., Gabrielsson J. \& Al-Saffar A. 2007. Comparison of the QT interval response during sinus and paced rhythm in conscious and anesthetized beagle dogs. J. Pharmacol. Toxicol. Methods 56:131144.

Peng S., Yu Y., Hao K., Xing H., Li D., Chen C., Huang A., Hong X., Feng Y., Zhang Y., Li J., Wang B., Wu D., Wang X. \& Xu X. 2006. Heart rate-corrected QT interval duration is significantly associated with blood pressure in Chinese hypertensives. J. Electrocardiol. 39:206-210.

Rasmussen C.E., Vesterholm S., Ludvigsen T.P., Haggstrom J., Pedersen H.D., Moesgaard S.G. \& Olsen L.H. 2011. Holter monitoring in clinically healthy Cavalier King Charles Spaniels, Wire-haired Dachshunds, and Cairn Terriers. J. Vet. Intern. Med. 25:460-468.

Raunig D., Depasquale M.J., Huang C.H., Winslow R. \& Fossa A.A. 2001. Statistical analysis of QT interval as a function of changes in RR interval in the conscious dog. J. Pharmacol. Toxicol. Methods 46:1-11.

Sivarajah A., Collins S., Sutton M.R., Regan N., West H., Holbrook M. \& Edmunds N. 2010. Cardiovascular safety assessments in the conscious telemetered dog: Utilisation of super-intervals to enhance statistical power. J. Pharmacol. Toxicol. Methods 62:12-19.

Spence S., Soper K., Hoe C.M. \& Coleman J. 1998. The heart rate-corrected QT interval of conscious beagle dogs: a formula based on analysis of covariance. Toxicol. Sci. 45:247-258.

Spier A.W., Meurs K.M., Muir W.W., Lehmkuhl L.B. \& Hamlin R.L. 2001. Correlation of QT dispersion with indices used to evaluate the severity of familiar ventricular arrhythmias in boxers. Am. J. Vet. Res. 62:1481-1485.

Tattersall M.L., Dymond M., Hammond T. \& Jean-Pierre Valentin J.P. 2006. Correction of QT values to allow for increases in heart rate in conscious Beagle dogs in toxicology assessment. J. Pharmacol. Toxicol. Methods 53:11-19.

Tilley L.P. 1992. Essentials of Canine and Feline Electrocardiography. $3^{\text {rd }}$ ed. Lea and Febiger, Philadelphia. 470p.

Topilski I., Rogowski O., Rosso R., Justo D., Copperman Y., Glikson M., Belhassen B., Hochenberg M. \& Viskin S. 2007. The morphology of the QT interval predicts torsade de pointes during acquired bradyarrhythmias. J. Am. Coll. Cardiol. 49:320-328.

Van de Water A., Verheyen J., Xhonneux R. \& Reneman R.S. 1989. An improved method to correct the QT interval of the electrocardiogram for changes in heart rate. J. Pharmacol. Methods 22:207-217.

Vanderlei L.C.M., Pastre C.M., Hoshi R.A., De Carvalho T.D. \& De Godoy M.F. 2009. Basic notions of heart rate variability and its clinical applicability. Revta Bras. Cirur. Cardiovasc. 24:205-217. 